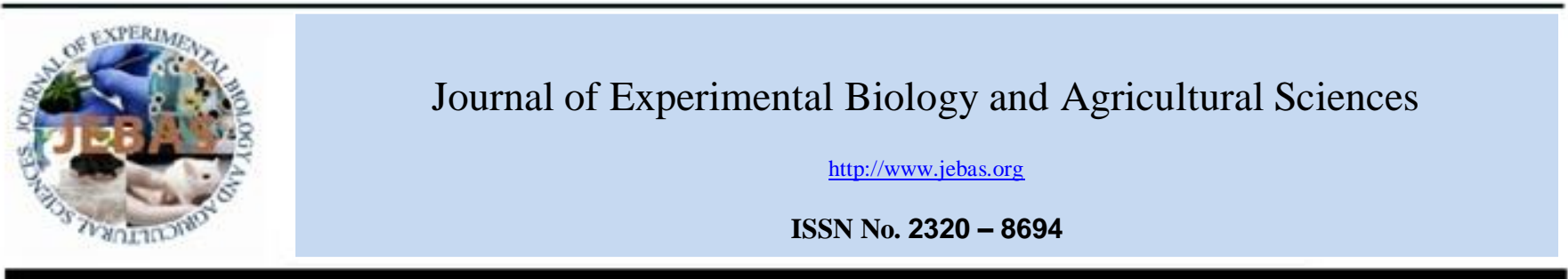

\title{
EFFECT ON IMMUNE RESPONSE AGAINST Pasteurella multocida CAPSULAR TYPE A:1 AND A:4 ON SUPPLEMENTATION WITH PROTEIN PURIFIED DERIVATIVES OF Mycobacterium bovis IN CHICKEN
}

\author{
Stanzin Zadon ${ }^{1}$, Vinod Kumar Chaturvedi ${ }^{2}$, Bablu Kumar ${ }^{3}$, Praveen Kumar Gupta ${ }^{4}$, Mayank \\ Rawat ${ }^{5}$, Varsha Paladan ${ }^{6}$
}

\footnotetext{
${ }^{1,6} \mathrm{PhD}$ scholars, Division of Bacteriology \& Mycology, Indian Veterinary Research Institute, Izatnagar, U.P. 243122, India

${ }^{2}$ Principal Scientist, Division of Biological Products, Indian Veterinary Research Institute, Izatnagar, U.P. 243122, India

${ }^{3}$ Senior Scientist, Division of Biological Products, Indian Veterinary Research Institute, Izatnagar, U.P. 243122, India

${ }^{4}$ Principal Scientist, Division of Veterinary Biotechnology, Indian Veterinary Research Institute, Izatnagar, U.P. 243122, India

${ }^{5}$ Principal Scientist, Division of Biological Standardization, Indian Veterinary Research Institute, Izatnagar, U.P. 243122, India
}

Received - October 21, 2017; Revision - November 10, 2017; Accepted - December 20, 2017

Available Online - December 27, 2017

DOI: http://dx.doi.org/10.18006/2017.5(6).780.785

\section{KEYWORDS}

Pasteurella multocida A:1

A:4

Tuberculo-protein

Montanide

ELISA

\begin{abstract}
The adjuvant potential of tuberculo-protein of Mycobacterium bovis and Montanide ISA-206 adjuvants in different combination with Pasteurella multocida serotype A:1 and A:4 whole cell antigens have been evaluated in chicken model. Four different groups of chicken were immunized with different combination of adjuvants and humoral immune response was assessed by indirect ELISA. The immune response study revealed that chicken immunized with whole cell antigen in combination with Protein precipitated derivative (PPD) as well as montanide ISA-206 elicited a robust humoral immune response. To assess the protective ability two groups of chicken immunized with P.multocida A:1 were challenged with 1 MLD of Pasteurella multocida A:1; whereas two other groups of chicken immunized with P.multocida A:4 bacterin were challenged with 100 MLD of P.multocida A:4. Challenge studies indicated that both the groups of chicken immunized with $P$. multocida A:1 whole cell antigen adjuvanted with both Montanide ISA-206 and Mycobacterium bovis PPD as well as only Montanide ISA-206 conferred $100 \%$ protection against $P$ multocida A:1. However two other groups immunized with P.multocida A:4 bacterins could not sustain 100 MLD dose of direct challenge and there were $100 \%$ death of all the birds in both the immunized group, but the group immunized with both Montanide and PPD showed delayed death.
\end{abstract}

* Corresponding author

E-mail: vkchaturvedi@mail.com (Vinod Kumar Chaturvedi)

Peer review under responsibility of Journal of Experimental Biology and Agricultural Sciences.

Production and Hosting by Horizon Publisher India [HPI] (http://www.horizonpublisherindia.in/).

All rights reserved.
All the article published by Journal of Experimental Biology and Agricultural Sciences is licensed under a Creative Commons Attribution-NonCommercial 4.0 International License Based on a work at www.jebas.org.

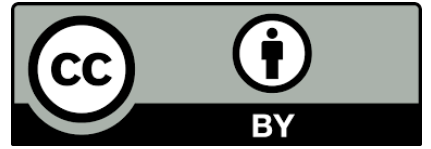




\section{Introduction}

Adjuvants plays important role in potentiating immune response and enhance protective ability of candidate vaccine antigen. Depending upon the nature of organism adjuvants are selected to get desired immune response. The humoral immune response plays vital role in clearance from body against those pathogens which are extra cellular in nature and whose antigen presentation is through the MHC class II. With few exceptions, alum is most widely used adjuvant approved for human and animal use in the majority of countries worldwide. Although alum is able to induce a good antibody (Th2) response, it has little capacity to stimulate cellular (Th1) immune responses which are important for protection against many pathogens (Vogel \& Powell, 1995). Freund et al., (1937) developed an emulsion of water and mineral oil containing killed Mycobacteria, thereby creating one of the most potent known adjuvants, Freund's complete adjuvant (FCA).

The adjunvanticity of bacteria derived adjuvants is mediated by $\mathrm{N}$-acetyl muramyl-L-alanyl-D-isoglutamine, also called MDP. MDP activates many different cell types including macrophages, leucocytes, endothelial cells and fibroblasts inducing the secretion of various cytokines such as IL-1, B-cell growth factor and fibroblast activating factor (Petrovsky \& Aguilar, 2004).

The oil in water emulsion without added Mycobacteria is known as Freund's incomplete adjuvant (FIA).Freund complete adjuvant (FCA) is considered better adjuvants in comparison to Freund incomplete adjuvant (FIA) which is due to killed Mycobacterial antigen. The use of Freund adjuvant is mainly restricted to hyper immune sera production as the animal may become sensitive to the tuberculo-protein. But this holds true only for those animals which are screened for tuberculosis by PPD. The large animals are tested for the tuberculosis by delayed type hypersensitivity therefore its use may have some limitations but the birds can be effectively immunized with formulations with tuberculo-protein if the formulation have positive effect on the immune response. Thus there is need to evaluate the potential of cellular components of Mycobacteria as an adjuvant with vaccine candidate in the species where it does not hinder testing procedure. The tuberculoprotein derivatives are better alternative in this direction. Further if such components are having adjuvant effect may be used effectively in vaccine formulation in those animals like birds where tuberculin testing is not done. Therefore potential of the purified protein derivative (PPD) of $M$. bovis along with Montanide formulation with Pasteurella multocida serotype A:1 and A:4 bacterin was explored in the birds following immunization. Pasteurella multocida type A:1 and A:4 was taken as target for the present study as it is the causative agent of disease called fowl cholera which is an acute, fatal and septicaemic disease of various domestic and wild bird species (Derieux, 1978; Glisson et al., 2013). In India it has been reported recurrently from the states of Assam (Lalrinthunga \& Burah, 1993), Gujarat (Pande, 1993), Maharashtra (Kulkarni et al.,1990) and Orissa (Panda et al.,1951). Hence realizing the significance of this poultry pathogen and potential application of tuberulo-protein in immune response enhancement the present pilot study was undertaken to investigate the effect of PPD derived from M.bovis on immune response of whole cell antigen of P.multocida type A:1 and A:4 causing fowl cholera.

\section{Materials and Methods}

\subsection{Preparation of Purified Protein derivatives}

The Purified Protein derivative from indigenous strain of Mycobacterium bovis cultured in Dorset Hanley medium was used for the study was prepared as per the methods described in OIE (2009). The growth was steamed for $3 \mathrm{~h}$ at $100^{\circ} \mathrm{C}$ and subsequently clarified with $0.2 \mu \mathrm{m}$ filter. The protein in culture filtrate was precipitated by adding $40 \%$ Trichloro acetic acid. After precipitation the centrifugation was done at 3,000 rpm for 30 minutes and supernatant was discarded. The precipitated protein was washed four times with $5 \% \mathrm{NaCl}(\mathrm{pH} 3.0)$ till $\mathrm{pH}$ of the protein was 2.7 . The protein precipitate was then dissolved in alkaline solution ( $\mathrm{pH}$ 6.6).The concentrate was then centrifuged to remove all insoluble impurities and then soluble proteins were diluted with glucose buffer solution (R-30). This was then tested for determination of protein concentration by Biuret method.

\subsection{Biomass production of Pasteurella multocida type A:1 and} A:4

\subsubsection{Pasteurella multocida}

Pasteurella multocida serotype A:1 and A:4 was procured from Division of Biological Standardization IVRI, Bareilly, was cultured on the $5 \%$ sheep blood agar and characterized based on morphological, cultural characteristics on different media along with molecular characterization.

\subsubsection{Production of bacterial harvest}

Both the organisms were cultured in Casein Sucrose Yeast (CSY) broth for $18 \mathrm{~h}$ at $37^{\circ} \mathrm{C}$. After examining each growth for purity and identity, $3 \mathrm{ml}$ of the same culture was used for sowing Roux flasks each containing 120-150 ml of CSY agar. The growth was harvested with the help of 10-20 ml of normal saline solution from each flask after incubation at $37^{\circ} \mathrm{C}$ for $24 \mathrm{~h}$, purity and identity was rechecked. The pooled growth of both P. multocida 
serotype A:1 and A:4 was then inactivated with $0.5 \%$ formalin and incubated for $24 \mathrm{~h}$. Each pooled growth was stored for a week at $4^{\circ} \mathrm{C}$.Before being manipulated for vaccine production the harvests were adjusted to Brown's opacity tube no. 7 and then retested for sterility and safety in the mice. The inactivated safe bacterial biomasses were subsequently used for immunization of PPD based adjuvant vaccine formulations for fowl cholera.

\subsection{Preparation of vaccine formulations}

Four different vaccine formulations using bacterial biomass from both ( $P$. multocida A:1 \& A:4) were prepared. First vaccine formulation was prepared using bacterial biomass from P.multocida A:1 adjuvanted with both Montanide as well as PPD where as second group of vaccine was prepared using only Montanide ISA-206 keeping the ratio of biomass and the Montanide (1:1) in water in oil formulation. Similarly third and fourth vaccine formulation was prepared using bacterial biomass from P.multocida A: 4. The emulsions were tested for viscosity and stability by drop test and were monitored for 9 months. PPD concentration in vaccine formulation was adjusted to $500 \mu \mathrm{g}$ per dose. All the vaccine formulations were tested for sterility. These formulations so prepared were tested for immune response studies in birds.

\subsection{Immunization trial}

\subsubsection{Grouping and rearing of birds}

Fourteen healthy, 11 week old (both sexes) white leghorn birds were divided in five groups as follows:

Group 1: P. multocida A:1 adjuvanted with PPD as well as Montanide ISA $206(\mathrm{n}=3$, birds) Group 2: P. multocida A:1 adjuvanted with only Montanide ISA $206(\mathrm{n}=3$, birds) Group 3: P. multocida A:4 adjuvanted with PPD as well as Montanide ISA 206 ( $\mathrm{n}=3$, birds) Group 4: P. multocida A:1 adjuvanted with only Montanide ISA $206(\mathrm{n}=3$, birds) and Group 5: Unvaccinated $(\mathrm{n}=$ 2, unvaccinated birds).

\subsubsection{Vaccination, blood collection and testing}

All the birds in different groups were vaccinated with one dose of $0.5 \mathrm{ml}$ deep intramuscular route. Blood was collected at weekly interval from 0 day to 6 weeks. The serum was separated aseptically and stored at $-20^{\circ} \mathrm{C}$ which was utilized for immune response studies.

\subsection{Monitoring of immune response}

Serum antibody titres of immunized birds were determined by indirect enzyme linked immunosorbent assay (ELISA) as per
Engvall \& Pearlman, 1972 with some modifications. P. multocida A:1 whole cell antigen was used for coating the plate as antigen. Optimum antigen, antibody and conjugate dilution were determined by checker board titration. Optical density was read at $492 \mathrm{~nm}$ using an ELISA Reader plate (ASYS Hitech, GMBH Austria, Expert plus). The results were expressed in terms of Positive /negative ratio.

\subsection{Determination of MLD of Pasturella multocida A:1 and A:4 and challenge studies}

P. multocida serotype A:1 and A:4 were inoculated into two mice so that the culture may be brought to Phase 1. After death of birds the organisms were reisolated in pure form from the heart blood on fresh $5 \%$ blood agar. The isolated organism was cultivated in $\mathrm{CSY}$ broth at $37^{\circ} \mathrm{C}$ for $18 \mathrm{~h}$. The dilutions of $18 \mathrm{~h}$ culture were prepared in fresh CSY broth was injected to birds. The dilution showing $100 \%$ death in the bird is taken as 1MLD. Challenge studies were done with 1MLD of A: 1 and 100 MLD of A: 4 of $P$. multocida.

\subsection{Data analysis}

All data were entered into Microsoft Office Excel sheet (Microsoft Corporation, 2013) and expressed as mean \pm SEM data were analyzed with one way ANOVA with individual groups.

\section{Results}

\subsection{Preparation of vaccine formulation}

Four different adjuvanted vaccine formulations prepared by seppic oil (Montanide), PPD protein and NSS containing whole cell $P$. multocida adjusted to Browns opacity tube no.7 mixture in the ratio of 1:1 in a high speed homogenizer $(14,000 \mathrm{rpm})$ for $1 \mathrm{~h}$ with 3 min interval of break after every $10 \mathrm{~min}$. After about five times of the mixing of the emulsion - thin, creamy white emulsions of low viscosity was formed. After that, emulsion was mixed in high speed blender (usually 10 times total) to form viscous emulsions which had flow times of approximately 1-3 minutes per $\mathrm{ml}$. These emulsions maintained their shape and remained largely submerged on addition to cold water. Moreover, these emulsions were highly stable, retaining their characteristic structure for more than 9 months when stored at $4^{0} \mathrm{C}$.

\subsection{Pathogenicity of the P.multocida strains}

Injection of P.multocida type A:1 (with 1MLD) induced 100\% protection in chicken immunized with $P$ multocida type A: 
bacterin formulation with or without PPD. A Challenge (100 MLD of $P$ multocida A:4) of immunized chicken with P.multocida type A:4 bacterin with or without PPD resulted into differential death pattern. The chicken immunized with type A:4 bacterin without PPD leads to death within 24 hours with apparently severe sickness. However, the P. multocida type A:4 bacterin with PPD showed mortality in the range of 36-48 hours.

3.3 Serum antibody titre in chicken immunized with adjuvanted $P$. multocida A1 bacterin

ELISA data showed differences in the onset, intensity and duration of the $P$. multocida type A:1 antibodies evoked by the different vaccine formulations from 7 day to 6 weeks. The serum antibody titers in both Montanide alone as well as Montanide \& PPD adjuvanted group (Table no.1 \& 2) showed classical pattern of immune response. Detectable antibody titer was found on $7^{\text {th }}$ DPI which peaked on $42^{\text {nd }}$ DPI in both the groups. Peak antibody titer in groups adjuvanted with both PPD \& Montanide was (3.14 \pm 0.22$)$ was higher than Montanide alone (2.62 \pm 0.53$)$.

Table 1 Humoral immune response in chicken immunized with Pasteurella multocida type A: 1 bacterin adjuvanted with montanide

\begin{tabular}{|cccccc|}
\hline $\begin{array}{c}\text { A1 without } \\
\text { PPD }\end{array}$ & 0 day & $\mathbf{7}$ day & $\mathbf{1 4}$ day & 21 day & $\mathbf{4 2}$ day \\
\hline 1 & 1.08 & 1.08 & 1.79 & 1.79 & 1.68 \\
\hline 2 & 1.07 & 1.09 & 1.16 & 2.06 & 3.52 \\
\hline 3 & 1.08 & 1.12 & 1.39 & 1.79 & 2.69 \\
\hline $\begin{array}{c}\text { Mean } \pm \text { S.E } \\
\text { Control }\end{array}$ & $1.075 \pm 0.03$ & $1.09 \pm 0.09$ & $1.45 \pm 0.19$ & $1.89 \pm 0.09$ & $2.63 \pm 0.53$ \\
$($ Mean \pm S.E) & $1.10 \pm 0.02$ & $1.05 \pm .02$ & $1.03 \pm .09$ & $1.12 \pm .07$ & 1.17475 \\
\hline
\end{tabular}

Table 2 Humoral immune response in chicken immunized with Pasteurella multocida type A:1 bacterin adjuvanted with montanide and tuberculo-protein of Mycobacterium bovis

\begin{tabular}{|cccccc|}
\hline $\begin{array}{c}\text { A1 with } \\
\text { PPD }\end{array}$ & 0 day & $\mathbf{7}$ day & $\mathbf{1 4}$ day & $\mathbf{2 1}$ day & 42 day \\
\hline 1 & $\mathbf{1 . 1 2 3}$ & $\mathbf{1 . 1 4}$ & $\mathbf{1 . 8 9}$ & $\mathbf{2 . 2 1}$ & 2.77 \\
\hline 2 & 1.04 & 1.23 & 1.74 & $\mathbf{2 . 5 7}$ & $\mathbf{3 . 1 0}$ \\
\hline 3 & 0.99 & 1.13 & 1.73 & 2.11 & 3.56 \\
\hline Mean \pm S.E & $1.05 \pm .04$ & $1.16 \pm .03$ & $1.79 \pm .06$ & $2.30 \pm 0.15$ & $3.14 \pm .23$ \\
\hline $\begin{array}{c}\text { Control } \\
(\text { Mean } \pm \text { S.E) }\end{array}$ & $1.09 \pm 0.02$ & $1.06 \pm .02$ & $1.01 \pm .01$ & $1.12 \pm .07$ & 1.18 \\
\hline
\end{tabular}

Journal of Experimental Biology and Agriculture Science http://www.jebas.org
3.4 Serum antibody titre in chicken immunized with adjuvanted $P$. multocida A:4 bacterin

The serum antibody titers as determined by Indirect ELISA in both Montanide alone as well as Montanide and PPD adjuvanted group (Table no. \& \& 4) showed classical pattern of immune response. Detectable antibody titer was found on $7^{\text {th }}$ DPI which peaked on $42^{\text {nd }}$ DPI in both the groups. Peak antibody titer in groups adjuvanted with both PPD \& Montanide was (2.66 \pm 0.36$)$ was higher than Montanide alone (2.27 \pm 0.30$)$.

Table 3 Humoral immune response in chicken immunized with Pasteurella multocida type A:4 adjuvanted with montanide

\begin{tabular}{|cccccc|}
\hline $\begin{array}{c}\text { A4 without } \\
\text { PPD }\end{array}$ & $\mathbf{0 ~ d a y}$ & $\mathbf{7}$ day & $\mathbf{1 4}$ day & $\mathbf{2 1}$ day & $\mathbf{4 2}$ day \\
\hline 1 & 1.08 & 1.07 & 1.12 & 1.37 & 2.58 \\
\hline 2 & 1.13 & 1.17 & 1.42 & 1.63 & Died \\
\hline 3 & 1.09 & 1.13 & 1.24 & 1.35 & 1.97 \\
\hline Mean \pm S.E & $1.10 \pm 0.02$ & $1.12 \pm 0.04$ & $1.26 \pm 0.09$ & $1.45 \pm 0.09$ & $2.28 \pm 0.31$ \\
\hline $\begin{array}{c}\text { Control } \\
\text { Mean } \pm \text { SE) }\end{array}$ & $1.01 \pm 0.02$ & $1.06 \pm .011$ & $1.01 \pm .01$ & $1.12 \pm .07$ & 1.18 \\
\hline
\end{tabular}

Table 4 Humoral immune response in chicken immunized with Pasteurella multocida type A:4 bacterin adjuvanted with montanide and tuberculo-protein of Mycobacterium bovis

\begin{tabular}{|cc|cccc|}
\hline $\begin{array}{c}\text { A4 with } \\
\text { PPD }\end{array}$ & $\mathbf{0}$ day & $\mathbf{7}$ day & $\mathbf{1 4}$ day & $\mathbf{2 1}$ day & $\mathbf{4 2}$ day \\
\hline 1 & 1.17 & 1.16 & 1.34 & 1.63 & 2.56 \\
\hline 2 & 1.08 & 1.17 & 1.33 & 1.83 & 3.08 \\
\hline 3 & 1.18 & 1.17 & 2.01 & 1.98 & 2.36 \\
\hline Mean \pm S.E & $1.15 \pm 0.05$ & $1.17 \pm 0.01$ & $1.56 \pm 0.39$ & $1.81 \pm 0.17$ & $2.67 \pm 0.37$ \\
\hline $\begin{array}{c}\text { Control } \\
\text { (Mean } \pm \text { S.E) }\end{array}$ & $1.01 \pm 0.02$ & $1.06 \pm .011$ & $1.01 \pm .01$ & $1.12 \pm .07$ & 1.18 \\
\hline
\end{tabular}

The immune response studies of both type A:1 and A:4 bacterin with tuberculo-protein vaccine showed that there was augmentation of immune response in both treated groups of birds in reference to control birds (Figure 1; Figure 2). The trends of immune response in both the treated groups were somewhat same. The significant variation in immune response was observed in between the both groups of tuberculo-protein vis a vis the formulations without tuberculo-protein.

\section{Discussion}

Fowl cholera is an acute, fatal and disease of economic importance in poultry production that may occur in different forms, such as peracute, acute, and chronic infections, often 


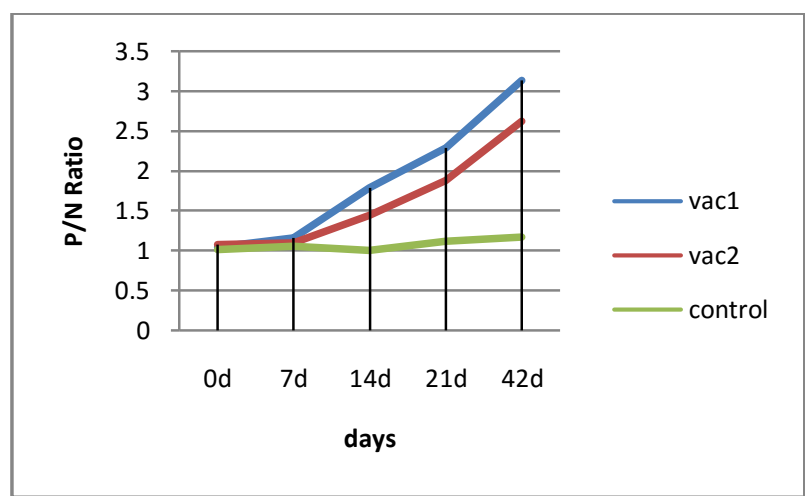

Figure 1 Humoral Immune response against Pasteurella multocida type A:1 in birds vaccinated montanide adjuvanted bacterin of Pasteurella mutocida type A:1 with and without tuberculoprotein of Mycobacterium bovis (Vaccine 1- A:1 with PPD, Vaccine 2- A:1 without PPD)

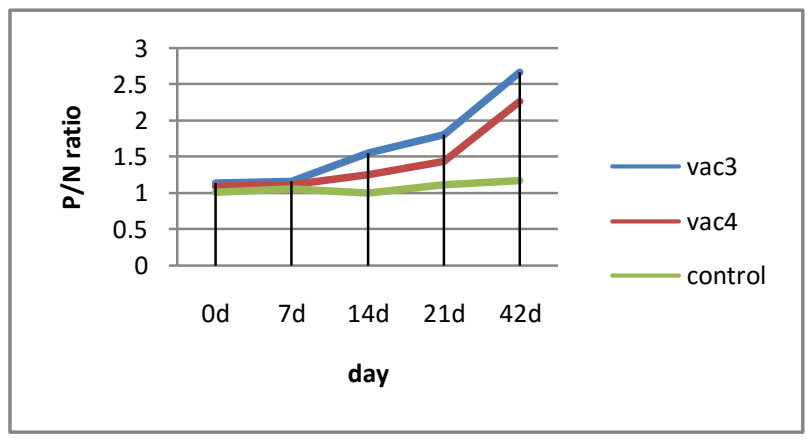

Figure 2 Humoral Immune response against Pasteurella multocida type A:4 in birds vaccinated montanide adjuvanted bacterin of Pasteurella mutocida type A:4 with and without tuberculoprotein of Mycobacterium bovis (Vaccine 3- A:4 with PPD, Vaccine 4- A:4 without PPD)

causing high morbidity and mortality, thus resulting in large financial losses (Hirsh et al., 1990; Christensen \& Bisgaard, 2000; OIE, 2015). The disease is caused by Pasteurella multocida serotype A:1, A:3, A:4 in birds and it has wide host range including domesticated chickens, turkeys, ducks, geese, quail, game birds reared in captivity, companion birds, birds in zoo and wild birds (Wang et al., 2009; OIE, 2015). Vaccines used against fowl cholera include inactivated bacterins or live attenuated bacteria. Bacterins are widely used, but must be injected and induce immunity only to homologous serotypes (Davis 1987; Rebers et al., 1988). In contrast, live vaccines can confer immunity against heterologous strains but may revert to virulence, possibly causing mortality in vaccinated flocks (Hofacre \& Glisson 1986; Hopkin et al., 1988; Christiansen et al., 1989).
However, despite years of research and control efforts in medication and vaccination practices fowl cholera has remained prevalent.

The limitations in fowl cholera vaccine lies that the current vaccine formulations in the vaccinated stock gives $80 \%$ protection upon challenge with less than 1MLD. Thus there is need to search for such adjuvants which may help to provide $100 \%$ protection upon challenege with 1 MLD or more. In the present study though $100 \%$ protection has been observed in both the type A:1 vaccinated birds but the immune response was comparatively higher in vaccine formulation having both Montanide as well as PPD. Thus the present formulation added with purified protein antigen is likely to provide better protection even to higher challenge dose of bacteria. The similar observation in vaccine formulation derived from P.multocida type A:4 support above observation as there is prolong survival time Thus the present proposition not only a new dimension to the fowl cholera vaccine but can be effectively used in other vaccine formulations as well.

The current co-adjuvanted vaccine with seppic oil and PPD for type A:1 and A:4 study indicated that the PPD may be a future adjuvant for the vaccine. The possibilities of tuberculo-protein as future adjuvant have also been explored in past and showed that it may be a promising adjuvant. The potential of individual proteins like M. tuberculosis protein 50S ribosomal protein L7/L12 (rplL) from Rv0652, as an immunoadjuvant has been explored as and found to have the efficacy of a for DC-based tumor immunotherapy ( Lee et al., 2014). The study conducted by the group indicated that Rv0652 induce DC maturation, and proinflammatory cytokine production (TNF-alpha, IL-1beta, and IL6) that is partially modulated by both MyD88 and TRIF signaling pathways. In our study, immune responses elicited by adjuvanted vaccine formulations indicated that the PPD may be used as an adjuvant. Since the tuberculo-protein is an admixture of series of proteins derived from Mycobacterial spp, role of individual protein needs to be investigated along with various bacterial, viral immunogen in different species of animals and subsequent studies on the molecular mechanism in reference to different species of animals. The study conducted thus validate the earlier observation of adjuvant potential (Lee et al., 2014) but this needs to be further validated in terms of cytokine genes expression and TLR induction with crude tuberculo-protein which will help in better understanding about mechanism of protection conferred by these adjuvants, so that in future this may be used as adjuvant which may provide multi-factorial effect on the immunity.

\section{Conclusion}

The present study revealed that protein purified derivatives can be effectively used in the vaccine formulation to enhance the immune response against the immunogens. Pasteurella multocida 
is an extracellular pathogen and purified protein derivatives have such a beneficial effect and it may likely to have sustainable effect on the intracellular organisms. Thus exhaustive studied be conducted in relation to various antigen encompassing bacterial, viral and protozoan pathogens. Simultaneously its role be further explored in immunotherapy of cancer as this may be the clean adjuvant. The findings clearly indicates that $100 \%$ protection can be provided in the oil based Pasteurella multocida vaccine formulation with co-adjuvantation with purified protein derivatives of Mycobacterium bovis and accordingly the vaccine validation protocols can then be further be modified.

\section{Acknowledgements}

The authors acknowledge with thanks to Dr Rishendra Verma, Scientist Emeritus for providing the growth of Mycobacterium bovis and Dr P.Joshi, Head, Veterinary Biochemistry for protein estimation by Biuret method. The authors also acknowledge the facilities provided by Director, Indian Veterinary Research Institute, Izatnagar.

\section{Conflict of Interest}

Authors would hereby like to declare that there is no conflict of interests that could possibly arise.

\section{References}

Christensen JP, Bisgaard M (2000) Fowl cholera. Revue scientifique et technique Office (International Epizootic) 19: 626637.

Christiansen KH, Carpenter TE, Snipes KP, Hird DW (1989) Transmission of Pasteurella multocida on California turkey premises in 1988-89. Avian Diseases 36: 262-271.

Davis RB (1987) Cholera and broiler breeders. Poultry Science 20:434-60.

Derieux WT (1978) Response of young chickens and turkeys to virulent and avirulent Pasteurella multocida administered by various routes. Avian Diseases 22: 131-139.

Engvall E, Pearlman P (1972) Enzyme-linked immunosorbent assay, ELISA. Quantitation of specific antibodies by enzymelabeled anti-immunoglobulin in antigen coated tubes. Immunology 109:129-135.

Freund J, Casals J, Hosmer EP (1937) Sensitization and antibody formation after injection of tubercle bacilli and parafin oil. Proceedings of the society for Experimental Biology and Medicine 37: 509-513.

Glisson JR, Hofacre CL, Christensen JP (2013) Diseases of Poultry. In: Swayne DE, Glisson JR, McDougald LR, Nolan LK, Suarez DL, Nair V (Eds.), Thirteenth Edition, Wiley Blackwell, Ames, Iowa, USA and Oxford, UK, Pp. 807-823.
Hirsh DC, Jessup DA, Snipes KP, Carpenter TE, Hird DW, McCapes RH (1990) Characteristics of Pasteurella multocida isolated from waterfowl and associated avian species in California. Journal of Wildlife Diseases 26: 204-209.

Hofacre CL, Glisson JR (1986) A serotypic survey of Pasteurella multocida isolated from poultry. Avian Diseases 30 : 632-623.

Hopkins BA, Huang THM, Olson LD (1998) Differentiating turkey post vaccination isolants of Pasteurella multocida using arbitrarily primed polymerase chain reaction. Avian Diseases 42 : 265-274.

Kulkarni DD, Karpe AG, Bannalikar AS, Gujar MB (1990) Biological observation on pasteurellosis in domestic animals and poultry. Indian Journal Comparative Microbiology, Immunology and Infectious Diseases 11: 22.

Lalrinthunga C, Baruah GK (1993) Mortality pattern of broilers in Assam. Indian Journal of Veterinary Pathology 2: 126-128.

Lee SJ, Shin SJ, Lee MH, Lee MG, Kang TH, Park WS, Soh BY, Park JH, Shin YK, Kim HW, Yun CH, Jung ID, Park YM ( 2014) A potential protein adjuvant derived from Mycobacterium tuberculosis Rv0652 enhances dendritic Cells-based tumor immunotherapy. Plos one 9: 104351.

OIE Manual of diagnostic tests and vaccines for terrestrial animals (2009) Bovine Tuberculosis. In Chapter 2.4.7 :1-16.

OIE Manual of diagnostic tests and vaccines for terrestrial animals (2015) Fowl cholera. In Chapter 2.3.9: 524-530.

Panda SN, Misra B, Das BC, Nayak BC (1951) An outbreak of Avian Pasteurellosis in Orissa. The Indian Veterinary Journal 58: 418-420.

Pande A (1993) Molecular studies on Indian isolates of Pasteurella multocida. M.V.Sc Thesis submitted to IVRI Deemed University, Izatnagar,U.P.

Petrovsky N, Aguilar JC (2004) Vaccine adjuvants: Current state and future trends. Immunology and Cell Biology $82: 488-496$.

Rebers PA, Jensen AE, Laird GA (1988) Expression of pili and capsule by the avian strain P-1059 of Pasteurella multocida. Avian Diseases 32: 313-318.

Vogel FR, Powell MF (1995) A summary compendium of vaccine adjuvants and excipients. In: Powell MF, Newman MJ (eds). Vaccine Design: the Subunit and Adjuvant Approach. New York: Plenum Publishing Corp, Pp. 234.

Wang C, Wu Y, Xing X, Guocheng HG, Jiayin DJ and Hongxuan H (2009) An Outbreak of Avian Cholera in Wild Waterfowl in Ordos Wetland, Inner Mongolia, China. Journal of Wildlife Diseases 45(4):1194-1197. 